\title{
Synergistic Effect of Triptolide and Tacrolimus on Rat Cardiac Allotransplantation
}

\author{
Ruzheng LI, ${ }^{1,2}$ MD, Kenji TAKAZAWA, ${ }^{1}$ MD, Hiromasa SuZUKI, ${ }^{3}$ MD, \\ Akifusa HARIYA, ${ }^{1}$ MD, Taira YAMAmoto,${ }^{1} \mathrm{MD}$, Satoshi MAtsushitA, ${ }^{1} \mathrm{MD}$, \\ Hitoshi Hirose, ${ }^{1} \mathrm{MD}$, and Atsushi AmANO, ${ }^{1} \mathrm{MD}$
}

\begin{abstract}
SUMMARY
Recent studies have shown that triptolide inhibits $\mathrm{T}$ cell activation through mechanisms different from those of cyclosporine A and tacrolimus and we postulated that triptolide might have a synergistic effect with tacrolimus to enhance immunosuppression. Using a F344 donor-to-Lewis recipient rat combination, we investigated the immunosuppressive effects of triptolide alone or in combination with tacrolimus on the survival of cardiac allografts. Recipients were treated with placebo, triptolide, tacrolimus, and triptolide in combination with tacrolimus at different doses. The median survival time (MST) was 8 days for placebo; 9.5, 11, 14 and 19 days for triptolide monotherapy at doses of $0.04,0.08,0.16$, and $0.32 \mathrm{mg} / \mathrm{kg} / \mathrm{day}$, respectively, and $11,13.5$, and 52 days for tacrolimus monotherapy at doses of $0.025,0.05$, and $0.1 \mathrm{mg} / \mathrm{kg} / \mathrm{day}$, respectively. Tacrolimus $0.025 \mathrm{mg} / \mathrm{kg} / \mathrm{day}$ combined with triptolide 0.08 and $0.16 \mathrm{mg} / \mathrm{kg} /$ day prolonged the MST to 17.5 and 20 days, respectively; while tacrolimus $0.05 \mathrm{mg} / \mathrm{kg} /$ day combined with triptolide $0.04,0.08$, and $0.16 \mathrm{mg} / \mathrm{kg} / \mathrm{day}$ prolonged the MST to 21,23 , and 23 days, respectively. These results suggest that triptolide is a moderately effective immunosuppressive agent. Triptolide combined with a subtherapeutic dose of tacrolimus produced a synergistic effect in prolonging rat cardiac allograft survival. (Jpn Heart J 2004; 45: 657-665)
\end{abstract}

Key words: Cardiac allografts, Immunosuppression, Triptolide, Tacrolimus, Combination therapy

DURING the past two decades, tremendous advances have been made in posttransplantation immunosuppressive therapy. Many new immunosuppressive drugs have been discovered and developed for clinical use in organ transplants. The high efficacy of immunosuppression of the calcineurin inhibitors, cyclosporine $\mathrm{A}(\mathrm{CsA})$ and tacrolimus, have contributed to improve the clinical outcome of

From the ${ }^{1}$ Department of Cardiovascular Surgery, Juntendo University School of Medicine, Tokyo, Japan, ${ }^{2}$ Department of Cardiovascular Surgery, the People's Hospital of Hainan Province, Hainan, PRC, and ${ }^{3}$ Department of Cardiology, Juntendo University School of Medicine, Tokyo, Japan.

This study was supported in part by the Sasagawa Medical Research Foundation.

Address for correspondence: Ruzheng Li, MD, Department of Cardiovascular Surgery, the People's Hospital of Hainan Province, Xiuhua Road 19, Xiuying, Haikou, Hainan, PRC.

Received for publication July 15, 2003.

Revised and accepted January 19, 2004. 
organ transplantations. At this time, CsA-based or tacrolimus-based immunosuppression remains the cornerstone of immunosuppressive therapies. ${ }^{1)}$

Tacrolimus is a macrolide isolated from streptomyces tsukubaensis. It was first demonstrated in 1984 to be immunologically effective in an in vivo rat heart allograft transplantation model. ${ }^{2}$ Since then, the mechanisms of tacrolimus have been intensively investigated. ${ }^{3-5)}$ Like CsA, tacrolimus inhibits the T-lymphocyte immune response via blockade of the calcium-dependent signaling pathway. ${ }^{4)}$ Furthermore, tacrolimus inhibits lymphocyte activation in vitro 10 to 100 times more potently than CsA. ${ }^{6}$ Tacrolimus is now being used as a primary immunosuppressant in clinical organ transplantations. ${ }^{5,79)}$ However, tacrolimus has doserelated side-effects, including nephrotoxicity, diabetogenesis, neurotoxicity, and it has also been shown to increase the incidence of infection and malignancies. ${ }^{7,910)}$ These adverse effects may restrict its clinical usage. The development of other immunosuppressive agents that act synergistically with tacrolimus, thereby permiting significant tacrolimus dose reduction, remains a compelling target in clinical organ transplantations.

Extracts of the Chinese herb Tripterygium Wilfordii Hook F (TWHF) exhibit potent immunosuppressive and anti-inflammatory properties and have been used extensively in China for the treatment of arthritis and other autoimmune diseases for many years. ${ }^{11,12)}$ Triptolide, a diterpenoid triepoxide compound purified from the root of TWHF, has been identified as one of the major components responsible for the immunosuppression of the herb. ${ }^{13)}$ The immunosuppressive activities of triptolide have been investigated both in vitro ${ }^{14,15}$ and in vivo. ${ }^{16,17)}$ Qiu and co-workers demonstrated that triptolide inhibits both calciumdependent and calcium-independent pathways and activates $\mathrm{T}$ cells via inhibition of interleukin-2 transcription at a site different from the targets of CsA or tacrolimus. ${ }^{18)}$ Based on these studies, we propose that triptolide might offer a new alternative for combined therapy with CsA or tacrolimus to enhance the therapeutic effects and to reduce the adverse effects of CsA or tacrolimus, which may allow tacrolimus to be used more effectively in clinical immunosuppression.

To the best of our knowledge, the immunosuppressive efficacy of triptolide combined with tacrolimus has not been reported. Therefore, we investigated the effects of triptolide alone or in combination with tacrolimus on graft survival in a major histocompatibility complex (MHC)-compatible rat cardiac allograft model.

\section{METHODS}

Animals: Adult male inbred F344 (RT1 lvl) and Lewis (RT1 1) rats weighing between 200 and $250 \mathrm{~g}$ were used as donors and recipients, respectively. Both 
were purchased from Charles River Japan, Ltd. (Atsugi, Japan). The rats were cared for in accordance with NIH regulations governing laboratory animals and housed in a specific pathogen-free room with controlled temperature and light/ dark cycles in our animal facility.

Agents: Tacrolimus obtained from Fujisawa Pharmaceuticals (Osaka, Japan) was dissolved in distilled water to make a $1 \mathrm{mg} / \mathrm{mL}$ stock solution and stored in a freezer $\left(-70^{\circ} \mathrm{C}\right)$. Final tacrolimus doses were diluted in saline to volumes of 0.1 $\mathrm{mL}$ containing treated doses, and it was administered to the animals intramuscularly. Triptolide obtained from Fujian Medical Science Research Institute (Fujian, China) was found to be $98 \%$ pure by reverse phase high-performance liquid chromatography (HPLC). A stock solution of triptolide was prepared by dissolving 10 $\mathrm{mg}$ of triptolide in $5 \mathrm{~mL}$ dimethyl sulfoxide (DMSO) and then stored at $-70^{\circ} \mathrm{C}$. Final triptolide doses were diluted in saline to a $1 \mathrm{~mL}$ volume containing treated doses, and it was administered to the animals intraperitoneally. The control animals received the vehicles of the two drugs at the same formulations.

Cardiac transplantation: The recipients were anesthetized with $40 \mathrm{mg} / \mathrm{kg}$ sodium pentobarbital intraperitoneally and supplemented with ether anesthesia. Heterotopic abdominal heart transplantation was performed by end-to-side anastomosis of the ascending aortic to the abdominal aorta and the pulmonary artery to the inferior vena cava, as described by Ono and Lindsey. ${ }^{19)}$ Cold ischemic time was less than 45 minutes. Cardiac graft activity was assessed daily by abdominal palpation. The time of rejection was defined as the last day of palpable contraction. This was confirmed by laparotomy if necessary.

Experimental groups: The transplanted rats were randomly assigned to one of the following groups for posttransplantation immunosuppressive treatment starting on the day of transplantation and continuing to the 13th posttransplantation day or the day of rejection: Group 1) saline and DMSO control $(n=6)$; Group 2) triptolide $0.04 \mathrm{mg} / \mathrm{kg} /$ day $(n=6)$; Group 3) triptolide $0.08 \mathrm{mg} / \mathrm{kg} / \mathrm{day}(n=7)$; Group 4) triptolide $0.16 \mathrm{mg} / \mathrm{kg} /$ day $(n=6)$; Group 5) triptolide $0.32 \mathrm{mg} / \mathrm{kg} / \mathrm{day}(n$ = 6); Group 6) tacrolimus $0.025 \mathrm{mg} / \mathrm{kg} / \mathrm{day}(n=6)$; Group 7) tacrolimus $0.05 \mathrm{mg} /$ $\mathrm{kg} /$ day $(n=6)$; Group 8$)$ tacrolimus $0.1 \mathrm{mg} / \mathrm{kg} / \mathrm{day}(n=6)$; Group 9) triptolide $0.08 \mathrm{mg} / \mathrm{kg} / \mathrm{day}+$ tacrolimus $0.025 \mathrm{mg} / \mathrm{kg} /$ day $(n=6)$; Group 10) riptolide 0.16 $\mathrm{mg} / \mathrm{kg} /$ day + tacrolimus $0.025 \mathrm{mg} / \mathrm{kg} / \mathrm{day}(n=7)$; Group 11) triptolide $0.04 \mathrm{mg} /$ $\mathrm{kg} /$ day + tacrolimus $0.05 \mathrm{mg} / \mathrm{kg} /$ day $(n=6)$; Group 12$)$ triptolide $0.08 \mathrm{mg} / \mathrm{kg} /$ day + tacrolimus $0.05 \mathrm{mg} / \mathrm{kg} /$ day $(n=9)$; Group 13) triptolide $0.16 \mathrm{mg} / \mathrm{kg} / \mathrm{day}+$ tacrolimus $0.05 \mathrm{mg} / \mathrm{kg} /$ day $(n=9)$.

Evaluation of drug interaction: The following equation described by Berenbaum ${ }^{20)}$ was used to evaluate the nature of the interaction between triptolide and tacrolimus:

dose of $\mathrm{A} / \mathrm{Ae}+$ dose of $\mathrm{B} / \mathrm{Be}=\mathrm{X}$. 
$\mathrm{A}$ is the dosage of drug $\mathrm{A}$ in combination with $\mathrm{B}$; Ae is the dosage of drug $A$ required to produce an effect equal to that achieved by $A$ in combination with $\mathrm{B}$; $\mathrm{B}$ is the dosage of drug $\mathrm{B}$ in combination with $\mathrm{A}$; $\mathrm{Be}$ is the dosage of drug $\mathrm{B}$ required to produce an effect equal to that achieved by $B$ in combination with $A$. $\mathrm{X}<1$ indicates synergy; $\mathrm{X}=1$ additivism; $\mathrm{X}>1$ antagonism. The equi-effective dosages of drug $\mathrm{A}(\mathrm{Ae})$ and drug $\mathrm{B}(\mathrm{Be})$ were determined from the dose-effect curves (Figure 1).

Histology: Except for those used for survival count, a total of 16 cardiac allografts from groups 1, 4, 7, and 13 (4 in each group respectively) were harvested 5 days after transplantation for histological examination. At autopsy, the transplanted hearts were removed, fixed in 10\% formalin solution, and embedded in paraffin. The specimen was sliced $4 \mu \mathrm{m}$ thick and stained with hematoxylineosin. Rejection scoring was recorded blindly according to the classification of the International Society of Heart and Lung Transplantation (ISHLT). ${ }^{21)}$ 0: no rejection (grade 0 ); 1 : focal, perivascular or interstitial infiltrate without necrosis (grade 1A); 2: diffuse but sparse infiltrate without necrosis (grade 1B); 3: one focus of aggressive infiltration and/or focal myocyte damage (grade 2); 4: multifocal aggressive infiltration and/or myocyte damage (grade 3A); 5: diffuse inflammatory process with necrosis (grade 3B); 6: diffuse, aggressive polymorphic infiltrate with edema, hemorrhage, vasculitis, and necrosis (grade 4). At sacrifice, the recipients' liver and kidney were also removed for histological assessment of drug toxicity.

Statistics: Survival data and ISHLT scores were analyzed by the Mann-Whitney U test using Statview 5.0 software. A $P$ value less than 0.05 was considered significant.

\section{RESULTS}

1. Effect of triptolide or tacrolimus monotherapy on graft survival: The survival times of F344 heart grafts transplanted to Lewis rats are described in Table I. The median graft survival time (MST) of the control group was 8 days. Daily treatment with triptolide prolonged the MST in a dose-dependent fashion: triptolide $0.04 \mathrm{mg} / \mathrm{kg} / \mathrm{day}$ had little effect on graft survival, with an MST of 9.5 days $(P=$ $0.5752)$; triptolide $0.08 \mathrm{mg} / \mathrm{kg} /$ day improved the MST to 11 days $(P=0.0453)$, triptolide $0.16 \mathrm{mg} / \mathrm{kg} / \mathrm{day}$ and $0.32 \mathrm{mg} / \mathrm{kg} /$ day improved it further to 14 days $(P=$ $0.0039)$ and 19 days $(P=0.0039)$, respectively. Similarly, tacrolimus at doses of $0.025,0.05$, and $0.1 \mathrm{mg} / \mathrm{kg} / \mathrm{day}$ prolonged the MST to $11(P=0.0453), 13.5(P=$ $0.0065)$, and 52 days $(P=0.0039)$, respectively. 
Table I. Effect of Triptolide and Tacrolimus on the Survival of F344 Heart Graft Transplanted to Lewis Rats

\begin{tabular}{|c|c|c|c|c|c|c|c|}
\hline Group & $\begin{array}{l}\text { Triptolide } \\
\text { (mg/kg/day) }\end{array}$ & $\begin{array}{l}\text { Tacrolimus } \\
\text { (mg/kg/day) }\end{array}$ & $n$ & Survival Day & MST (day) & $P$ value & $\mathrm{X}$ value \\
\hline 1 & 0 & 0 & 6 & $9,9,8,8,8,7$ & 8 & & \\
\hline 2 & 0.04 & 0 & 6 & $12,11,11,8,7,7$ & 9.5 & 0.5752 (vs.1) & \\
\hline 3 & 0.08 & 0 & 7 & $16,16,14,11,10,8,8$ & 11 & 0.0453 (vs.1) & \\
\hline 4 & 0.16 & 0 & 6 & $21,15,14,14,13,12$ & 14 & 0.0039 (vs.1) & \\
\hline 5 & 0.32 & 0 & 6 & $22,21,19,19,19,18$ & 19 & 0.0039 (vs.1) & \\
\hline 6 & 0 & 0.025 & 6 & $15,14,11,11,10,7$ & 11 & 0.0453 (vs.1) & \\
\hline 7 & 0 & 0.05 & 6 & $20,15,15,12,11,9$ & 13.5 & 0.0065 (vs.1) & \\
\hline 8 & 0 & 0.1 & 6 & $>100,>100,54,50,30,21$ & 52 & 0.0039 (vs. 1$)$ & \\
\hline 9 & 0.08 & 0.0025 & 6 & $23,19,18,17,17,14$ & 17.5 & $\begin{array}{l}0.0082 \text { (vs. } 3 \text { ) } \\
0.0082 \text { (vs.6) }\end{array}$ & 0.71 \\
\hline 10 & 0.16 & 0.025 & 7 & $21,21,20,20,20,19,13$ & 20 & $\begin{array}{l}0.1004 \text { (vs.4) } \\
0.0066 \text { (vs.6) }\end{array}$ & 0.82 \\
\hline 11 & 0.04 & 0.05 & 6 & $26,24,21,21,17,15$ & 22 & $\begin{array}{l}0.0027 \text { (vs. } 2 \text { ) } \\
0.0163 \text { (vs. } 7 \text { ) }\end{array}$ & \\
\hline 12 & 0.08 & 0.05 & 9 & $\begin{array}{l}31,28,26,25, \\
23,21,20,14,11\end{array}$ & 23 & $\begin{array}{l}0.0070 \text { (vs. } 3) \\
0.0251 \text { (vs.7) }\end{array}$ & 0.85 \\
\hline 13 & 0.16 & 0.05 & 9 & $\begin{array}{l}>100,29,24,23 \\
23,21,20,19,19\end{array}$ & 23 & $\begin{array}{l}0.0056 \text { (vs. } 4) \\
0.0039 \text { (vs.7) }\end{array}$ & 1.0 \\
\hline
\end{tabular}

MST = median survival time; $P$ value = calculated by Mann-Whitney $\mathrm{U}$ test $\mathrm{X}$ value $=$ calculated by Berenbaum equation.

2. Effect of triptolide in combination with tacrolimus on graft survival: The median graft survival times in recipients treated with triptolide in combination with tacrolimus were significantly longer than those in the monotherapy groups (Table I, Figure 1). Tacrolimus $0.025 \mathrm{mg} / \mathrm{kg}$ /day combined with triptolide at doses of 0.08 and $0.16 \mathrm{mg} / \mathrm{kg} /$ day extended the MST to 17.5 (X $=0.71$ by Berenbaum equation) and 20 days $(X=0.82)$, respectively. Tacrolimus $0.05 \mathrm{mg} / \mathrm{kg} /$ day combined with triptolide at doses of $0.04,0.08$, and $0.16 \mathrm{mg} / \mathrm{kg} / \mathrm{day}$ produced a similar extension, with MSTs of 21, $23(\mathrm{X}=0.85)$, and 23 days $(\mathrm{X}=1.0)$, respectively.

3. Histological evaluation: Histological examination of untreated control cardiac allografts removed 5 days after transplantation showed aggressive lymphocyte infiltration with congestion, edema, hemorrhage and severe myocyte necrosis (Figure 2A). Allografts treated with triptolide $0.16 \mathrm{mg} / \mathrm{kg}$ /day showed multifocal lymphocyte infiltration with mild to moderate myocyte damage (Figure 2B). Allografts treated with tacrolimus $0.05 \mathrm{mg} / \mathrm{kg} /$ day demonstrated marked reduction of lymphocyte infiltration with mild myocyte damage (Figure 2C). In contrast, the allografts treated with a combination of tacrolimus $0.05 \mathrm{mg} / \mathrm{kg} / \mathrm{day}$ and triptolide $0.16 \mathrm{mg} / \mathrm{kg} /$ day showed only focal, perivascular lymphocyte infiltration without myocyte damage (Figure 2D). Drug toxicity studies demonstrated that there were no histological abnormalities observed in the liver or kidney of the recipients. 
A

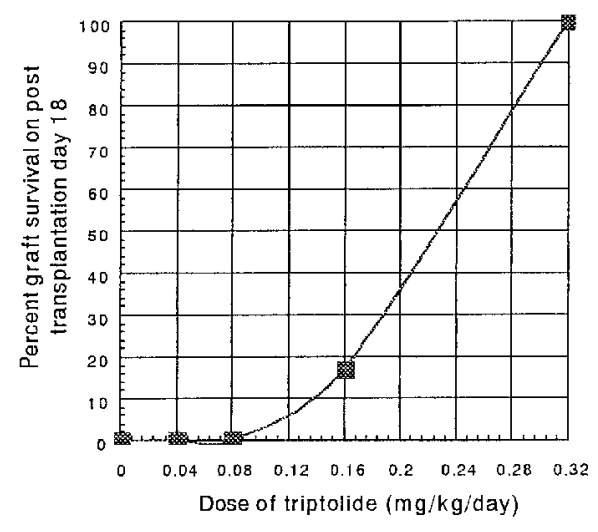

B

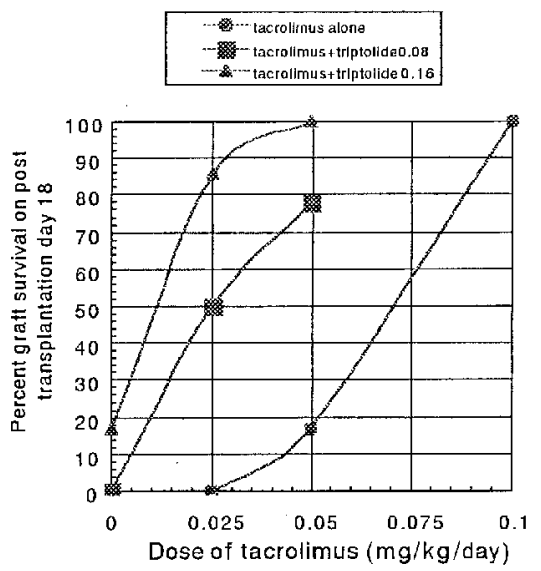

Figure 1. Dose-effect curve of triptolide (A) and dose-effect curves of tacrolimus alone and in combination with triptolide at doses of 0.08 and $0.16 \mathrm{mg} / \mathrm{kg} /$ day $(\mathbf{B})$ to produce $100 \%$ cardiac allograft survival on posttransplantation day 18 (the 10-day prolongation of untreated cardiac allograft survival) are shown.

A

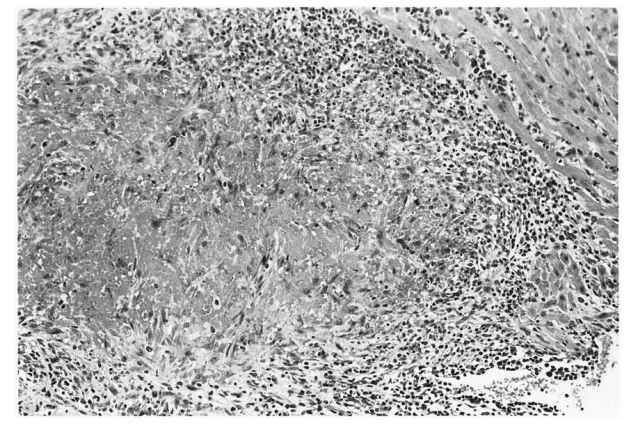

C

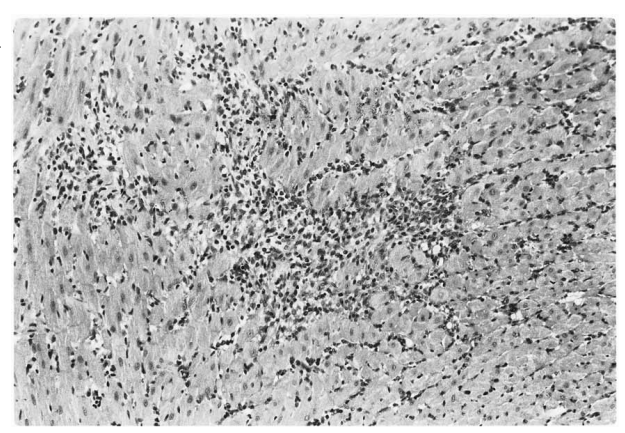

D

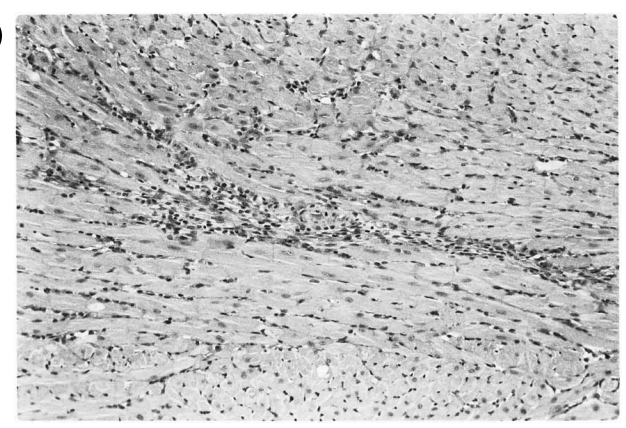

Figure 2. Representative histological photos of rat cardiac allograft removed 5 days after transplantation. A: Untreated control allografts showed aggressive lymphocyte infiltration with edema, hemorrhage, and severe myocyte necrosis. B: Allografts treated with triptolide $0.16 \mathrm{mg} / \mathrm{kg} /$ day demonstrated obvious infiltration by lymphocytes with mild to moderate myocyte damage. C: Allografts treated with tacrolimus $0.05 \mathrm{mg} / \mathrm{kg} /$ day showed a marked reduction in lymphocyte infiltration with mild myocyte damage. D: Allografts treated with combined triptolide $0.16 \mathrm{mg} / \mathrm{kg} /$ day and tacrolimus $0.05 \mathrm{mg} / \mathrm{kg} /$ day revealed mild, focal, perivascular lymphocyte infiltration without myocyte damage. (Hematoxylin and eosin staining. Original magnification $\times 100$ ). 
Table II. ISHLT Scores of Allografts Removed 5 Days After Transplantation

\begin{tabular}{lccc}
\hline Treatment & ISHLT Score & Mean \pm SD & $P$ value \\
\hline Control $(n=4)$ & $5,5,6,4$ & $5.0 \pm 0.8$ & \\
Triptolide $0.16 \mathrm{mg} / \mathrm{kg} /$ day $(n=4)$ & $3,4,3,5$ & $3.8 \pm 1.0$ & 0.11 \\
Tacrolimus $0.05 \mathrm{mg} / \mathrm{kg} /$ day $(n=4)$ & $3,3,2,3$ & $2.8 \pm 0.50$ & 0.021 \\
Triptolide $0.16 \mathrm{mg} / \mathrm{kg} /$ day \\
$\quad+$
\end{tabular}

ISHLT $=$ International Society of Heart and Lung Transplantation; $P$ value = calculated by Mann-Whitney U test.

The ISHLT scores of allografts removed 5 days after transplantation are shown in Table II. The ISHLT score decreased from 5.0 \pm 0.8 in untreated control to $3.8 \pm 1.0$ for triptolide $0.16 \mathrm{mg} / \mathrm{kg} / \mathrm{day}(P=0.11)$, to $2.8 \pm 0.5$ for tacrolimus $0.05 \mathrm{mg} / \mathrm{kg} / \mathrm{day}(P=0.021)$, and to $1.8 \pm 1.0$ for triptolide $0.16 \mathrm{mg} / \mathrm{kg} / \mathrm{day}$ in combination with tacrolimus $0.05 \mathrm{mg} / \mathrm{kg} /$ day $(P=0.021)$.

\section{DISCUSSION}

In this study, we evaluated the immunosuppressive efficacy of triptolide in prolonging the survival of allografts and in potentiating the immunosuppressive effects of tacrolimus with a MHC-compatible F344- to -Lewis rat cardiac allotransplantation model. The results showed that triptolide prolonged the cardiac allograft survival in a dose-dependent fashion. Using the equation of Berenbaum, we found that tacrolimus in combination with triptolide had a synergistic effect ( $\mathrm{X}=0.71 \sim 1.0$ ). The histological studies revealed that the ISHLT score was significantly decreased by a combined treatment of triptolide $0.16 \mathrm{mg} / \mathrm{kg} / \mathrm{day}$ and tacrolimus $0.05 \mathrm{mg} / \mathrm{kg} / \mathrm{day}$.

The Berenbaum equation was employed to evaluate the nature of the drug interaction between triptolide and tacrolimus. As recommended by Berenbaum, we choose a 10-day prolongation of untreated cardiac allograft survival (survival up to day 18 after transplantation in this study) as the equal specified effect of triptolide and tacrolimus. As shown in Figure 1, the dose of tacrolimus required to obtain $100 \%$ graft survival on posttransplantation day 18 can be reduced 5-fold when combined with $0.16 \mathrm{mg} / \mathrm{kg} /$ day triptolide. Tacrolimus has a relatively narrow therapeutic window (blood level of 5 to $15 \mathrm{ng} / \mathrm{mL}$ by TMX analysis). ${ }^{22)} \mathrm{A}$ high concentration of tacrolimus increases the risk of toxicities, whereas reduction of the dose sometimes leads to rejection. Therefore, therapy using tacrolimus in a subtherapeutic dose combined with another drug that acts synergistically is highly desired. The synergistic characteristics of triptolide in combination with tacrolimus may be of clinical significance. 
It is well known that complete $\mathrm{T}$ lymphocyte activation requires antigenmediated triggering of the $\mathrm{T}$ cell receptor/CD3 complex (signal 1) in conjunction with costimulatory signals provided by the CD28 molecule (signal 2). ${ }^{23)}$ Tacrolimus inhibits $\mathrm{T}$ cell activation via the CD3 pathway, while the CD28 pathway remains unaffected. ${ }^{24)}$ By contrast, triptolide inhibits $\mathrm{T}$ cell activation and triggers IL-2 gene expression through a CD28 costimulatory molecule resistant to CsA and tacrolimus. ${ }^{18)}$ The synergistic effect between triptolide and tacrolimus can be partially explained by their different mechanisms of action. With this novel mechanism of immunosuppression, triptolide may offer a new alternative for combined therapy with tacrolimus and broaden the therapeutic window of clinical immunosuppression.

In conclusion, triptolide is a moderately effective immunosuppressive agent that can act synergistically with tacrolimus to prolong rat cardiac allograft survival. Although further investigation is required to evaluate the mechanisms of interaction between these two drugs, the combination of triptolide with a subtherapeutic dose of tacrolimus might be an alternative strategy in organ transplantations.

\section{REFERENCES}

1. Denton MD, Magee CC, Sayegh MH. Immunosuppressive strategies in transplantation. Lancet 1999; 353: 1083-91.

2. Ochiai T, Nakajima K, Hashimoto M, et al. Effect of a new immunosuppressive agent, FK506, on heterotopic cardiac allotransplantation in the rat. Transplant Proc 1987; 19: 1284-6.

3. Schreiber SL, Crabtree GR. The mechanism of action of cyclosporine A and FK506. Immunol Today 1992; 13: $136-42$.

4. Liu J, Farmer JJ, Lane WS, Friedman J, Weissman I, Schreiber SL. Calcineurin is a common target of cyclophilin-cyclosporine A and FK506 complexes. Cell 1991; 66: 807-15.

5. Spencer CM, Goa KL, Gillis JC. Tacrolimus: an update of its pharmacology and clinical efficacy in the management of organ transplantation. Drugs 1997; 54: 925-75.

6. Kino T, Inamura N, Sakai F, et al. Effect of FK506 on human mixed lymphocyte reaction in vitro. Transplant Proc 1987; 19: 36-9.

7. Jain A, Reyes J, Kashyap R, et al. Liver transplantation under tacrolimus in infants, children, adults, and seniors: long-term results, survival, and adverse events in 1000 consecutive patients. Transplant Proc 1998; 30: 1403-4.

8. Woodle ES, Thistlethwaite JR, Gordon JH. Tacrolimus therapy for refractory acute renal allograft rejection: A prospective multicenter trial. Tacrolimus Kidney Transplantation Rescue Study Group. Transplant Proc 1996; 28: 3163-4.

9. Pham SM, Kormos RL, Hattler BG, et al. A prospective trial of tacrolimus (FK506) in clinical heart transplantation: Intermediate-term results. J Thorac Cardiovasc Surg 1996; 111: 764-72.

10. Hebert MF, Ascher NL, Lake JR, Robert JP. Efficacy and toxicity of FK 506 for the treatment of resistant rejection in liver transplant patients. Transplantation Proc 1991; 23: 3109-10.

11. Tao XL, Sun Y, Dong Y, et al. A prospective, controlled, double blind, cross-over study of tripterygium wilfordii hook F in treatment of rheumatoid arthritis. Chin Med J 1989; 102: 327-32.

12. Tao X, Davis LS, Lipsky PE. Effect of an extract of the Chinese herbal remedy Tripterygium Wilfordii Hook F on human immune responsiveness. Arthritis Rheum 1991; 34: 1274-81. 
13. Gu WZ, Chen R, Brandwein S, McAlpine J, Burres N. Isolation, purification and characterization of immunosuppressive compounds from tripterygium: triptolide and tripdiolide. Int J Immunopharmacol 1995; 17: 351-6.

14. Yang SX, Xie SS, Gao HL, Ma DL, Long ZZ. Triptolide suppresses T-lymphocyte proliferation by inhibiting interleukin-2 receptor expression, but spares interleukin-2 production and mRNA expression. Int J Immunopharmacol 1994; 16: 895-904.

15. Lu H, Hachida M, Enosawa S, Li XK, Suzuki S, Koyanagi H. Immunosuppressive effect of triptolide in vitro. Transplant Proc 1999; 31: 2056-7.

16. Yang SX, Gao HL, Xie SS, Zhang WR, Long ZZ. Immunosuppression of triptolide and its effect on skin allograft survival. Int J Immunopharmacol 1992; 14: 963-9.

17. Wang J, Xu R, Jin R, Chen Z, Fidler JM. Immunosuppressive activity of the Chinese medicinal plant Triptergium wilfordii. I. Prolongation of rat cardiac and renal allograft survival by the PG27 extract and immunosuppressive synergy in combination therapy with cyclosporine. Transplantation 2000; 70: 447-55.

18. Qiu D, Zhao G, Aoki Y, et al. Immunosuppressant PG490 (triptolide) inhitits T-cell interleukin-2 expression at the level of purine-box/nuclear factor of activated T-cells and NF-kappaB transcriptional activation. J Biol Chem 1999; 274: 13443-50.

19. Ono K, Lindsey ES. Improved technique of heart transplantation in rats. J Thorac Cardiovasc Surg 1959; 57 : 225.

20. Berenbaum MC. Synergy, additivism and antagonism in immunosuppression: a critical review. Clin Exp Immunol 1977; 28: 1-18.

21. Billingham ME, Cary NR, Hammond ME, et al. A working formulation for the standardization of nomenclature in the diagnosis of heart and lung rejection: Heart Rejection Study Group. The International Society for Heart Transplantion. J Heart Transplant 1990; 9: 587-93.

22. McMaster P, Buist L. FK506 in transplantation. Transplant Proc 1993; 25: 2684-5.

23. Gudmundsdottir H, Turka LA. T cell costimulatory blockade: new therapies for transplant rejection. J Am Soc Nephrol 1999; 10: 1356-65.

24. Kay JE, Benzie CR. T lymphocyte activation through the CD28 pathway is insensitive to inhibition by the immunosuppressive drug FK506. Immunol lett 1989; 23: 155-60. 